\title{
Physiological and psychological effects of acute intentional hyperventilation*
}

\author{
Bruce A. Thyer, $\dagger$ James D. Papsdorf and Phillip Wrjght \\ Department of Psychiatry, The University of Michigan Hospitals, Ann Arbor, MI 48109, U.S.A.
}

(Received 5 January 1984)

\begin{abstract}
Summary-Research is reviewed which suggests that hyperventilation syndrome is an underdiagnosed disorder for the presentation of many patients experienciug apparent anxiety states. In a test of this hypothesis, 21 normal individuals ( 9 female) underwent a $2 \mathrm{~min}$ period of intentional hyperventilation following a $10 \mathrm{~min}$ baseline phase. Hyperventilation was accompanied by increased subjective anxiety and tachycardia, and indications of peripheral vasoconstriction. Following hyperventilation, $S$ s experienced increased levels of state anxiety and perceived autonomic arousal, as indexed by self-report instruments. These resuits support the hypothesis that undiagnosed hyperventilatory phenomena may be etiologically implicated in states of pathologic anxiety.
\end{abstract}

\section{INTRODUCTION}

In recent years, it has become increasingly evident that patients apparently suffering from anxiety states are actually experiencing symptoms secondary to hyperventilation (Lum, 1975; Campernolle, Hoogduin and Joelle, 1979). The reported incidence of hyperventilation syndrome has heen estimated to range from 6 to $10 \%$ of patients seen by medical specialists (Lum, 1977) and the syndrome is characterized by a broad spectrum of physiological and psychological effects similar to those experienced by patients with Generalized Anxiety Disorder, Panic Disorder or Agoraphobia (American Psychiatric Association, 1980). Apart from general practice, patients with hyperventilation syndrome are often initially seen in emergency rooms, cardiology departments and neurology clinics, only to be eventually referred to psychiatrists or psychologists when no organic basis can be determined for the patient's myriad and complex array of symptoms.

Hyperventilation can be simply defined as the maintenance of ventilatory efforts in excess of metabolic needs, and is not usually detectable through behavioral observation of the patient's breathing (Magarian, 1982). The presence of frequent sighing, complaints of a dry mouth, and observing the patient licking his lips are suggestive indications for hyperventilation and the diagnosis can be more definitely arrived at through a hyperventilation challenge test. If acute intentional hyperventilation for several minutes reproduces many of the patient's symptoms, then the behavioral treatment should be directed toward the modification of breathing patterns (Lum, 1976; Cooke, 1979). Such simple procedures as bagrebreathing or having the patient hold several breaths can produce dramatic reductions in symptomatology (Kerr, Dalton and Gliebe, 1937). Hyperventilation syndrome is known to occur in children and adolescents (Enzer and Walker, 1967) and long-term follow-up studies have shown that a large proportion of child hyperventilators retain the habit as adults and often present as suffering from chronic anxiety (Herman, Stickler and Lucas, 1981). When correctly diagnosed, the prognosis for patients with hyperventilation syndrome is quite good, however, with $80-90 \%$ of patients significantly improving (Campernolle et al., 1979; Lum, 1976).

Much of what is known about hyperventilation syndrome is based upon practitioners' clinical experience with patients suffering from the disorder. Hyperventilation rapidly produces respiratory alkalosis which may lead to cerebral vasoconstriction, a wide range of neurological symptoms such as syncope, dizziness, tingling in the extremities and numerous other complaints, such as shortness of breath, tremors, weakness, subjective fear and chest pain (Lum, 1975). The similarity of this symptomatic picture to that seen in the anxiety disorders in obvious. Somewhat surprisingly, hyperventilation syndrome is not listed as a differential diagnosis for any of the anxiety disorders (American Psychiatric Association, 1980).

Although it is known that hyperventilation and anxiety are intimately related, the directionality of this relationship remains unclear. Most research on the effects of hyperventilation in normal $S \mathrm{~s}$ concerns the areas of blood chemistry changes and hemodynamics (see review by Magarian, 1982). It is known that acute anxiety may lead to hyperventilation in both patients and normal $S$ s (Magarian, 1982), and that hyperventilation reportedly leads to anxiety symptomatology in patients (Stead and Warren, 1973; Lum, 1975). Relatively little work, however, has been conducted on the psychological and physiological effects of hyperventilation in normal $S$ s. The present study was designed to determine if acute, intentional hyperventilation in normal individuals would result in increases in subjective and autonomic measures of anxicty. Failure to find such a directional relationship would weaken the hypothesis that hyperventilation syndrome is an etiology for apparent anxiety states, as postulated by Lum (1975) and others (Campernolle et al., 1979; Cooke, 1979; Tucker, 1963).

\section{Subjects}

\section{METHOD}

The $S$ s were 21 adults ( 9 female) with a mean age of $21 \mathrm{yr}$. All $S$ s were undergraduate students and in good health.

\section{Measures}

Anxiety was measured using the Subjective Units of Distress Scalc (SUDS), a 100-point analogue rating scale, with 0

\footnotetext{
*Portions of this paper were presented at the Annual Meeting of the Association for Advancement of Behavior Therapy, New York, 8-11 December, 1983.

†T whom all correspondence should be addressed.
} 
representing complete relaxation and 100 maximum anxiety or panic (Wolpe, 1973). A further self-report index of anxiety was the State-Trait Anxiety Inventory (STAI; Spielberger, Gorsuch and Lushene, 1970), a 20-item rapidly completed pencil-and-paper measure. The STAI has a range of scores from 20 to 80 , with higher rating reflective of increased acute anxiety.

Autonomic measures of anxiety included heart rate (HR), peripheral vasoconstriction (finger temperature, FT) and Borkovec's (1976) Autonomic Perception Questionnaire (APQ). HR was monitored with a Gulf and Western Cardiotach (Model 4600), with the photoplethysmograph attached to the index finger of the $S$ 's left hand. The $S$ 's HR in beats per minute $(\mathrm{bpm})$ was displayed based upon the average beat-to-beat interval every $4 \mathrm{sec}$. Peripheral vasoconstriction was monitored with an Autogen $2000 \mathrm{~B}$ feed back thermometer. The thermister was attached to the middle finger of the $S^{\circ} \mathrm{s}$ left hand. Both HR (Obrist, 1976) and peripheral vasoconstriction (Thyer. Papsdurf, Davis and Vallecorsa, 1984) are known to be associated with autonomic arousal and are commonly employed in research on anxiety. The APQ is a $37-i t e m$ pencil-and-paper measure which has the $S$ report the extent (s)he is presently experiencing a number of autonomic symptoms. The APQ has a range of scores from 0-138, with higher scores reflective of increased perceived autonomic arousal.

\section{Procedure}

After the $S$ arrived at the laboratory, (s)he was seated facing the experimenter at a table in a sound-attenuated chamber and had the sensors attached to his/her left hand. All $S$ s were then given the following instructions:

This is a study of the physiological effects of a brief period of rapid breathing. I will record data from your sensors for $10 \mathrm{~min}$, then ask you to breathe rapidly for $2 \mathrm{~min}$, to be followed by a second $10 \mathrm{~min}$ period of normal breathing. During the experiment, please remain still and try not to talk. Do you have any questions?

Any questions were answered and the SUDS scaic explained to the $S$. The first baseline was beyun and measures recorded of the S's SUDS, HR and FT every $30 \mathrm{sec}$. At the end of $10 \mathrm{~min}$, the experimenter administered the STAI and the APQ. When the pencil-and-paper measures were complete the experimenter stated, "Alright, I'd like you to begin breathing
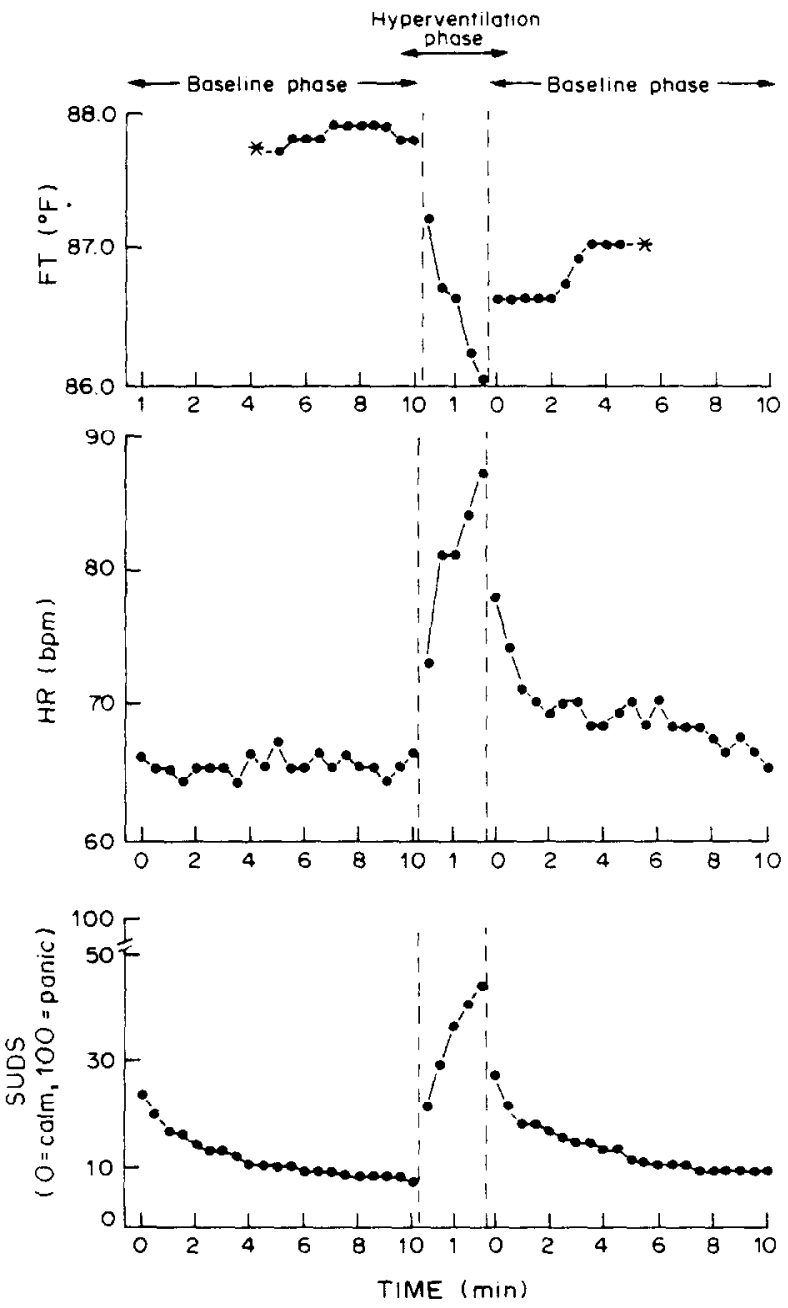

Fig. 1. Mean FT, HR and SUDS values during each time Interval. *Data not available. 
Table 1. Mean SUDS, HR and FI scores during each experimental period

\begin{tabular}{|c|c|c|c|c|c|c|}
\hline \multirow{3}{*}{$\begin{array}{l}\text { Dependent } \\
\text { measure }\end{array}$} & \multicolumn{6}{|c|}{ Time period } \\
\hline & \multicolumn{2}{|c|}{ First baseline } & \multicolumn{2}{|c|}{$\begin{array}{c}\text { Hyperventilation } \\
\text { phase }\end{array}$} & \multicolumn{2}{|c|}{ Second baseline } \\
\hline & $\bar{X}$ & $S D$ & $\bar{X}$ & $S D$ & $\bar{X}$ & $S D$ \\
\hline SUDS & 10.77 & 5.86 & 33.86 & 19.17 & 12.60 & 8.44 \\
\hline HR (bpm) & 65.59 & 11.66 & 81.04 & 14.58 & 68.91 & 14.09 \\
\hline FT ( $\left.{ }^{C} F\right)$ & 87.20 & 7.49 & 86.55 & 7.25 & 86.40 & 7.51 \\
\hline
\end{tabular}

Table 2. Mean STAI and APQ scores pre- and post-hyperventilation

\begin{tabular}{|c|c|c|c|c|}
\hline \multirow[b]{3}{*}{ Dependent measure } & \multicolumn{4}{|c|}{ Time period } \\
\hline & \multicolumn{2}{|c|}{$\begin{array}{l}\text { Immediately before } \\
\text { hyperventilation }\end{array}$} & \multicolumn{2}{|c|}{$\begin{array}{l}\text { Immediately after } \\
\text { hyperventilation }\end{array}$} \\
\hline & $\vec{X}$ & $\mathrm{SD}$ & $\bar{X}$ & $\mathrm{SD}$ \\
\hline $\begin{array}{l}\text { STAI } \\
\text { APQ }\end{array}$ & $\begin{array}{l}33.33 \\
12.57\end{array}$ & $\begin{array}{l}7.25 \\
7.54\end{array}$ & $\begin{array}{l}44.57 \\
27.66\end{array}$ & $\begin{array}{r}9.12 \\
14.65\end{array}$ \\
\hline
\end{tabular}

rapidly at about one breath per second like this". The experimenter demonstrated the proper breathing rate and volume and then asked the $S$ to begin. HR, SUDS and FT were recorded at 30-sec intervals during the 2 min of hyperventilation. The STAI and APQ were administered immediately after the cessation of rapid breathing. Measures were recorded during the second baseline phase as in the initial period.

\section{RESULTS}

The SUDS, HR and FT data were averaged for all $S$ s at each $30-\mathrm{sec}$ interval of the experiment. These values are displayed in Fig. 1 and indicates that acute. intentional hyperventilation was associated with increased subjective anxiety, mild Lachycardia and an apparent decrease in FT. The data for each separate phase of the experiment were averaged and these mean values and their standard deviations are presented in Table 1. A one-way ANOVA for repeated measures was conducted on the mean scores for each dependent variable across the three phases and revealed a significant effect for subjective anxiety changes $[F(2,18)=20.47, P<0.0001]$ and for $\operatorname{HR}[F(2,18)=22.47, P<0.0001]$. A similar analysis performed on FT scores failed to reach significance $[F(2,18)=1.18, P=0.32]$. The mean data for STAI and APQ scores taken pre- and post-hyperventilation is displayed in Table 2 . As assessed by pairwise $t$-tests, both state anxiety $(l=6.36$, $P<0.001)$ and perceived autonomic arousal $(t=-5.86, P<0.001)$ were observed to significantly increase following hyperventilation. These data support the hypothesis that brief periods of hyperventilation can produce acute and significant changes in an individual's level of anxiety, as assessed by a number of self-report measures of subjective discomfort (SUDS, STAI scores) and autonomic arousal (APQ scores), and by HR. Changes in FT observed during hyperventilation also suggested that increased peripheral vasoconstriction, a well-established index of anxiety, was also a sequelae to excessive ventilatory efforts.

\section{DISCUSSION}

Previous studies have found that various stress-induction procedures can produce mild hyperventilation (Garssen, 1980; Suess, Alexander, Smith, Sweeney and Marion, 1980). The present results clearly document the converse, acute hyperventilation can result in fairly dramatic and pervasive physiological and psychological effects. The immediate consequences of hyperventilation include clinically significant elevations in subjective anxiety, moderate tachycardia, mild peripheral vasoconstriction (cold hands?) and a much greater sensitivity to autonomic arousal. These documented effects of hyperventilation bear a striking resemblance to the symptomatic profile presented in Generalized Anxiety Disorder and the apparently 'spontaneous' attacks of acute anxiety characteristic of Panic Disorder and Agoraphobia (American Psychiatric Association, 1980).

There is some additional evidence which bears on the contingency relationships between hyperventilatory phenomena and states of pathologic anxiety. A number of clinical reports have documented the efficacy of $\mathrm{CO}_{2}$ therapy in reducing neurotic anxiety (Wolpe, 1973; Latimer, 1977). Somewhat better controlled investigations have also shown that brief inhalations of $\mathrm{CO}_{2}$ decrease the subjective anxiety in both neurotic patients (van den Hout and Griez, 1982; Slater and Leavy. 1966) and normal Ss (Ley and Walker, 1973), as well as reducing chronic anxiety in patients with lactate-inducable panic attacks (Haslam, 1974).

The present data documenting the anxiety-inducing effects of acute rapid breathing and previous research on the anxiolytic effects of $\mathrm{CO}_{2}$ therapy, suggest that more careful consideration be given to hyperventilatory phenomena as a differential diagnosis for apparent anxiety disorders than the current diagnostic criteria indicate. A hyperventilation challenge may be given to patients not currently anxious, or brief breath-holding or a bag-rebreathing test conducted on individuals acutely anxious, in order to test the hypothesis that the patient is suffering from hyperventilation syndrome. If the diagnosis is supported, relatively simple behavioral treatments may provide the patient with significant relief (Campernolle et al., 1979; Lum, 1976; Cooke, 1979).

\section{REFERENCES}

American Psychiatric Association (1980) Diagnostic and Statistical Manual of Mental Disorders (DSM-III), 3rd edn. APA, Washington, D.C

Borkovec T. (1976) Physiological and cognitive processes in the regulation of anxiety. In Consciousness and Self-regulation (Edited by Schwartz G. and Shapiro D.), pp. 261-308. Plenum Press, New York.

Campernolle T.. Hoogduin K. and Joele L. (1979) Diagnosis and treatment of the hyperventilation syndrome. Psychosomatics 20, 612-625. 
Cooke D. (1979) Hyperventilation: its treatment and relation to anxiety. Behav. Therapist 2(5), 32-33.

Enzer N. and Walker P. (1967) Hyperventilation syndrome in childhood. J. Pediat. 70, 521-532.

Garssen B. (1980) Role of stress in the development of the hyperventilation syndrome. Psychother. Psychosom. 33, $214-225$.

Haslam M. (1974) The relationship between the effect of lactate infusion on anxiety states and their amelioration by carbon dioxide inhalation. Br. J. Psychiat. 125, 88-90.

Herman S., Stickler G. and Lucas A. (1981) Hyperventilation syndrome in children and adolescents: long-term follow-up. Pediatrics 67, 183-187.

van den Hout M. and Griez E. (1982) Cardiovascular and subjective responses to inhalation of carbon dioxide: a controlled test with anxious patients. Psychother. Psychosom. 37, 75-82.

Kerr W., Dalton J. and Gliebe P. (1937) Some physical phenomena associated with the anxiety states and their relation to hyperventilation. Ann. intern. Med. 11, 962-992.

Latimer L. (1977) Carbon dioxide as a reciprocal inhibitor in the treatment of neurosis. J. Behav. Ther. exp. Psychiat. 8, 83-85.

Ley R. and Walker H. (1973) Effects of carbon dioxide-oxygen inhalation on heart rate, blood pressure, and subjective anxiety. J. Behav. Ther. exp. Psychiat. 4, 223-228.

Lum L. (1975) Hyperventilation: the tip and the iceberg. J. psychosom. Res. 19, 375-383.

Lum L. (1976) The syndrome of chronic habitual hyperventilation. In Modern Trends in Psychosomatic Medicine, Vol. 3 (Edited by Hill O.). Butterworths, London.

Lum L. (1977) Breathing exercises in the treatment of hyperventilation and chronic anxiety states. Chest, Heart Stroke J. 2, 6-11.

Magarian G. (1982) Hyperventilation syndromes: infrequently recognized common expressions of anxiety and stress. Medicine 61, 219-236.

Obrist P. (1976) The cardiovascular-behavioral interaction-as it appears today. Psychophysiology 13, 95-107.

Slater S. and Leavy A. (1966) The effects of inhaling a $35 \% \mathrm{CO}_{2}-65 \% \mathrm{O}_{2}$ mixture upon anxiety level in neurotic patients. Behav. Res. Ther. 4, 309-316.

Spielberger C., Gorsuch R. and Lushene R. (1970) Manual for the State-Trait Anxiety Inventory. Consulting Psychologists Press, Palo Alto, Calif.

Stead E. and Warren J. (1973) The role of hyperventilation in the production, diagnosis and treatment of certain anxiety symptoms. Am. J. med. Sci. 206, 183-190.

Suess W., Alexander A., Smith D., Sweeney H. and Marion R. (1980) The effects of psychological stress on respiration: a preliminary study of anxiety and hyperventilation. Psychophysiology 17, 535-540.

Thyer B., Papsdorf J., Davis R. and Vallecorsa D. (1984) Autonomic correlates of the Subjective Anxiety Scale. J. Behav. Ther. exp. Psychiat. In press.

Tucker I. (1963) Hyperventilation in differential diagnosis. Med. Clins N. Am. 47, 491-497.

Wolpe J. (1973) The Practice of Behavior Therapy, 2nd edn. Pergamon Press, New York. 